Vol. 11 (4): 911-918 (2021)

\title{
CONFIDENTIALITY AND PRIVACY IN ALBANIAN HEALTHCARE
}

\author{
Andia Meksii ${ }^{1}$, Enkelejda Shkurti ${ }^{*}$, Bardhyl Çipi $^{2}$ \\ ${ }^{I}$ National Institute of Public Health, Tirana, Albania; \\ ${ }^{2 *}$ University of Medicine, Tirana, Albania, Faculty of Medicine, Tirana. Albania; \\ "Corresponding Author Enkelejda Shkurti, e-mail: enkeleda.shkurti@umed.edu.al;
}

Received July 2021; Accepted August 2021; Published September 2021;

DOI: https://doi.org/10.31407/ijees11.431

\begin{abstract}
In modern times, Confidentiality and Privacy principles are reflected in all international and national legislations. Since the formulation of these principles in the Hippocratic Oath and until their emergence in international ethical documents, such as the Oath of Geneva, Confidentiality and Privacy will constantly be the cornerstone of good medical practice. In this paper the authors have summarized some concepts of medical Confidentiality and Privacy, their roles in respecting and protecting the interest of patients and the interest of society that the medical profession can best serve the protection of people's health. Later some historical, ethical, juridical information on them are given as an extension of Medical Deontology in response to new developments in medicine. In the last part of the paper the authors have reflected the situation of Medical Confidentiality and Privacy in Albania and their role to improve the practice of medicine in the current situation of Albania.
\end{abstract}

Keywords: Confidentiality, privacy, Albania healthcare. 